\title{
Knowledge, Attitude and Practice and Associated Factors Towards Post-Operative Pain Management Among Nurses Working at St. Paul Hospital Millennium Medical College, Addis Ababa, Ethiopia, 2019
}

\author{
Jalale Benti ${ }^{1} \quad$ Feyissa Lemessa $^{2 *}$ Hikma Shukre $^{2}$ \\ 1.Nordic Medical Center, Addis Ababa, Ethiopia \\ 2.St. Paul's Hospital Millennium Medical College, Nursing Department, Addis Ababa, Ethiopia
}

\begin{abstract}
Background: Patients' recovery after surgery is one of the most important health processes in hospital healthcare. Effective pain management requires precise knowledge; attitude and competent assessment skills on practice. There is limited evidence on nurses' knowledge, attitude and practice of post-operative pain management (POPM) in Ethiopia. The present study aimed to assess Knowledge, Attitudes and Practices of Nurses Regarding POPM at St. Paul's Hospital Addis Ababa, Ethiopia.

Objective: To assess factors associated with knowledge, attitude and practice on postoperative pain management practice among nurses at St. Paul Hospital Millennium Medical College.

Methodology: Descriptive cross-sectional survey will be used. Study Area: St. Paul referral hospital. Source population: All surgical and operation room (OR) nurses of St. Paul's hospital. Study Period is from April- July 2019.

Result: The result of this study shows that generally nurses are knowledgeable in POPM. The result reveals that $23(14 \%)$ of surgical nurses have in adequate knowledge and $146(86 \%)$ have adequate knowledge regarding POPM. in attitude study nurses showed negative attitude towards the questioners they were given. Nurses tend to have poor practice regarding POPM according to this study.

Conclusion: The results also show that the nurses have negative attitudes regarding patients experiencing pain and the use of placebo. The study found that the practices of nurses related to POPM pain are at low level. As the nurses are the most important parts in the multidisciplinary approach in pain management, their knowledge and attitude make a big difference on practice POPM. So, there is a need for regular in-service education on pop management according to the recommendation of standard.
\end{abstract}

Keywords: Knowledge, Attitude, Practice, Post-Operative, Pain Management, Nurses

DOI: $10.7176 / \mathrm{JMPB} / 69-03$

Publication date:March $31^{\text {st }} 2021$

\section{Introduction}

Pain is a distressing feeling often caused by intense or damaging stimuli. According to the international association for the study of pain," pain is defined as an unpleasant sensory and emotional experience associated with actual and potential tissue damage. (1)

The American Society of Anesthesiologists (ASA) defined pain in the postoperative setting as pain that is present in a surgical patient because of a preexisting surgical procedure, or a combination of diseased-related and procedure related resources. Patients frequently experience moderate to severe pain in the postoperative period. Adequate level of knowledge and positive attitude are essential components in the delivery of post-operative pain management.(2)

According to the available data, less than half of surgical patients report adequate postoperative pain relief. Surgery-related trauma usually induces postoperative pain which should be alleviated as quickly and effectively as possible. According to statistics, clinical management of postoperative pain is far from being perfect, despite significant advancements in evidence-based knowledge. (3)

Although the pain management is an integral and important part of the nursing care, studies suggest that, nursing management of postoperative pain remains inadequate. Untreated and undertreated pain has a significantly interferes with the patient's physical, emotional and spiritual well-being, thus can alter the patient's quality of life.(1)

Unrelieved postoperative pain has been shown to increase the rate of postoperative complications (e.g., atelectasis, pneumonia, thromboembolism, depressed immune function, prolonged hospital stays) and the risk of developing chronic postoperative pain. Numerous studies have revealed that the prevalence of pain remains high in post-operative patients. Unrelieved pain from post-surgery has devastating physiological, psychological, and socio-economic effects.(1)

Therefore, nurses should have a solid foundation of knowledge about post-operative pain management and develop a positive attitude towards it to assess patients' condition and to deliver individualized care to each one 
to reduce discomfort and enhance the quality of life.

The importance of postoperative pain management has been repeatedly demonstrated in the past two decades. Effective management of post-operative pain can lead to comfort, better mobility, better recovery, shorter stay in hospital improvement, better breathing, less strain on the heart in mobilization, decreased duration of hospital confinement, reduced hospital costs, and increased level of patient satisfaction.(1)

Pain can be considered as the fifth vital sign and protocols, team work, and regular pain evaluations are need to reinforce postoperative pain management. (4)

Patients' recovery after surgery is one of the most important health processes in hospital healthcare. Effective pain management requires precise knowledge; attitude and competent assessment skills on practice. Nurses should have a solid foundation of pain knowledge and develop a correct attitude towards post-operative pain management.(2)

Patients frequently experience moderate to severe pain in the postoperative period. Although the pain management is an integral and important part of the nursing care, studies suggest that, nursing management of postoperative pain remains inadequate. (3)

The American Society of Anesthesiologists (ASA) defined pain in the postoperative setting as pain that is present in a surgical patient because of a preexisting surgical procedure, or a combination of diseased-related and procedure related resources. (2)

Incidence of postoperative pain (POP) has been reported to be between $47-100 \%$. It has been repeatedly confirmed by studies in the past 3 to 4 decades that 20 to $80 \%$ of patients undergoing surgery suffer from inadequately treated pain and pain is classified as a serious public health problem both in the developed and in developing countries. Insufficient education and training for nurses and patients were amongst the issues reported as poor post-operative pain management. Although studies have shown that pain education programs increase nurses' knowledge and improve attitudes towards pain management, the management of post-operative pain by nurses still remains a problem(2)

A study conducted in Addis Ababa on Assessment of postoperative pain management revealed that the prevalence of moderate to severe postoperative pain was found to be $28.6 \%$. This indicates that Postoperative pain was insufficiently managed in this hospital. (4)

The present study is aimed to assess KAP of Nurses Regarding POPM at St. Paul hospital.

\section{Material and methods}

Study Area and Period

Saint Paul Hospital Millennium College SPHMMC is located at Gulele sub city, Addis Ababa Ethiopia. It was built by Emperor Haile Selassie in 1969 with the help of the German Evangelical Church. It aimed to serve the poor. The hospital has 350 beds totally. An average of 380,000 clients are served annually. It has catchment population of more than 5million. The hospital had 1200 clinical and non-clinical staff. Out of these staff there are 960 nurses in OPD (neonatal, pediatrics \& adult), medical \& surgical ward, major \& minor OR, recovery, emergency, labor, ENT ward \& OR, psychiatry, onchology, dermatolog, dental, ophthalmology, transplant ward \& OR.

Study Period: was from April- August, 2019

\section{Study Design}

A Descriptive cross-sectional survey was used

\section{Source population and Study population}

Source Population

All surgical and operation room (OR) nurses of St. Paul's hospital who have worked in their respective department for more than six months.

\section{Study Population}

Nurses who work at surgical wards, maxillo facial \& ENT, OR and surgical ward, recovery nurses, transplant ward and OR nurses at SPHMMC.

\section{Sample Size Determination and Sampling Technique}

Simple random sampling technique was used. They involve random selection procedures to ensure that each unit of the sample is chosen on the basis of chance. All units of the study population should have an equal or at least a known chance of being included in the sample.

\section{Sample size determination}

Sample size is calculated using a formula for single population proportion. 
$\mathrm{n}=\frac{(\mathrm{z} \alpha / 2)^{2} \mathrm{p}(\mathrm{q})}{\mathrm{d}^{2}}$

Where $\mathrm{n}=$ sample size

$\mathrm{Z}=$ Reliability Coefficient with $95 \%$ confidence interval

$\mathrm{P}=$ Population proportion assume to be $50 \%=0.5$

$\mathrm{q}=1-\mathrm{p}$ proportion of the population, $\mathrm{d}=$ Margin of error $5 \%(0.05)$, N-Total study population

Then, $\mathrm{n}=\frac{(\mathrm{z} \alpha \backslash 2)^{2} \mathrm{P}(1-\mathrm{P})}{\mathrm{d}^{2}}=\frac{(1.96)^{2} 0.5(1-0.5)}{(0.05)^{2}}=384.16$

Since, our total population is less than 10,000 . We use correction formula was used and the final sample size was $=169$

\section{Operational Definition}

- Knowledge: means the nurses' perception and understanding of post-operative pain management based on experience.

This categorize as good knowledge and poor knowledge

- Good Knowledge: is the Knowledge Status of nurses when they scored more than the mean.

- Poor knowledge: is the Knowledge Status of nurses when they scored less than the mean.

- Attitude: refer to the nurses' behavior and way of acting towards effective pain management. This is categorized as Favorable attitude and Unfavorable attitude.

- Positive attitude: is the category of nurses when they scored more than the mean value.

- Negative attitude: is the category of nurses when they scored less than the mean value.

- Practice: Means the nurses skill on post-operative pain management based on their experience.

○ Good practice: is the practice Status of nurses when they scored more than the mean.

- Poor practice: is the practice Status of nurses when they scored less than the mean.

- Trained: Nurses who have got at least one training on pain assessment and management either on the job or off the job.

\section{Data Collection Tools and Techniques}

The data was collected using a semi-structured self-administered questionnaire which was adopted and developed by reviewing similar literatures. Objectives of the study, relevance of the study, procedures during data collection, confidentiality of client information, eligibility criteria, respondents' right, informed consent, ways of approach were maintained during the data collection.

\section{Data Quality Assurance}

The questionnaire was prepared in English researchers to check for consistency of the questionnaire. Maintenance of privacy and confidentiality of the respondents as well as good communication skills between respondents and researchers contributed for the quality of the study. Every day all questionnaires was reviewed and checked at the end of data collection period and any errors corrected accordingly.

\section{Data Analysis}

The data was entered, cleaned and analyzed using SPSS version 23. Descriptive analysis of the data using frequency, proportion, percentage and mean was also be done. Logistic regression was employed to determine whether there is association between dependent and independent variables, demographic and general characteristics. And the findings of the study was presented in tables and graphs.

\section{Results}

Socio-demographic characteristics

A total of 169 structured questionnaires were distributed to both male and female nurses working in postoperative area. Among the total of 169 patients 58(34.3\%) male while 111(65.7\%) were female. With mean age of 31.21 and SD of 7.347. Regarding educational status while 12(7.1\%) diploma holders, 141(83.4\%), 16 $(9.5 \%)$ were degree and masters respectively. About $64(37.9 \%)$ of study participants have $2-5$ years' work experience and almost 70(41.4\%) of nurses working at surgical ward (Table 2). 
Table 2: Socio-demographic characteristics of nurses working in surgical department of selected hospitals in Addis Ababa, Ethiopia, 2019(n=169)

\begin{tabular}{|c|c|c|c|}
\hline Sociodemographic characteristics & & Frequency & Percent \\
\hline \multirow[t]{2}{*}{ Sex } & Male & 58 & 34.3 \\
\hline & Female & 111 & 65.7 \\
\hline \multirow[t]{3}{*}{ Age } & $19-30$ yrs & 104 & 61.7 \\
\hline & $31-40$ yrs & 49 & 23.2 \\
\hline & $>=40 \mathrm{yrs}$ & 16 & 9.6 \\
\hline \multirow[t]{3}{*}{ Educational level } & Diploma & 12 & 7.1 \\
\hline & Degree & 141 & 83.4 \\
\hline & Masters & 16 & 9.5 \\
\hline \multirow[t]{6}{*}{ Year of experience } & less than 2 years & 39 & 23.1 \\
\hline & 2 to 5 years & 64 & 37.9 \\
\hline & 5 to 10 years & 29 & 17.2 \\
\hline & 10 to 15 years & 17 & 10.1 \\
\hline & 15 to 20 & 5 & 3.0 \\
\hline & $>20$ years & 15 & 8.9 \\
\hline \multicolumn{4}{|l|}{ Current area of practice } \\
\hline & Surgical ward & 70 & 41.4 \\
\hline & Recovery & 24 & 14.2 \\
\hline & OR & 19 & 11.2 \\
\hline & Maxillo facial & 34 & 20.1 \\
\hline & Transplant OR & 10 & 5.9 \\
\hline & Transplant ward & 12 & 7.1 \\
\hline \multicolumn{4}{|c|}{ Year of experience in postop \& surgical area } \\
\hline & $<2$ years & 94 & 55.6 \\
\hline & 2 to 5 years & 43 & 25.4 \\
\hline & 5 to 10 years & 10 & 5.9 \\
\hline & 11 to 15 years & 10 & 5.9 \\
\hline & 16 to 20 years & 5 & 3.0 \\
\hline & $>20$ years & 7 & 4.1 \\
\hline
\end{tabular}

Knowledge among Nurses of SPHMMC towards POPM

The nurses were considered as having adequate knowledge if they scored more than mean out of 13 in the knowledge assessment questionnaire. The nurses were considered as having inadequate knowledge if they scored less than mean. The result reveals that 23(14\%) of surgical nurses have in adequate knowledge and $146(86 \%)$ have adequate knowledge regarding POPM (Fig 2).

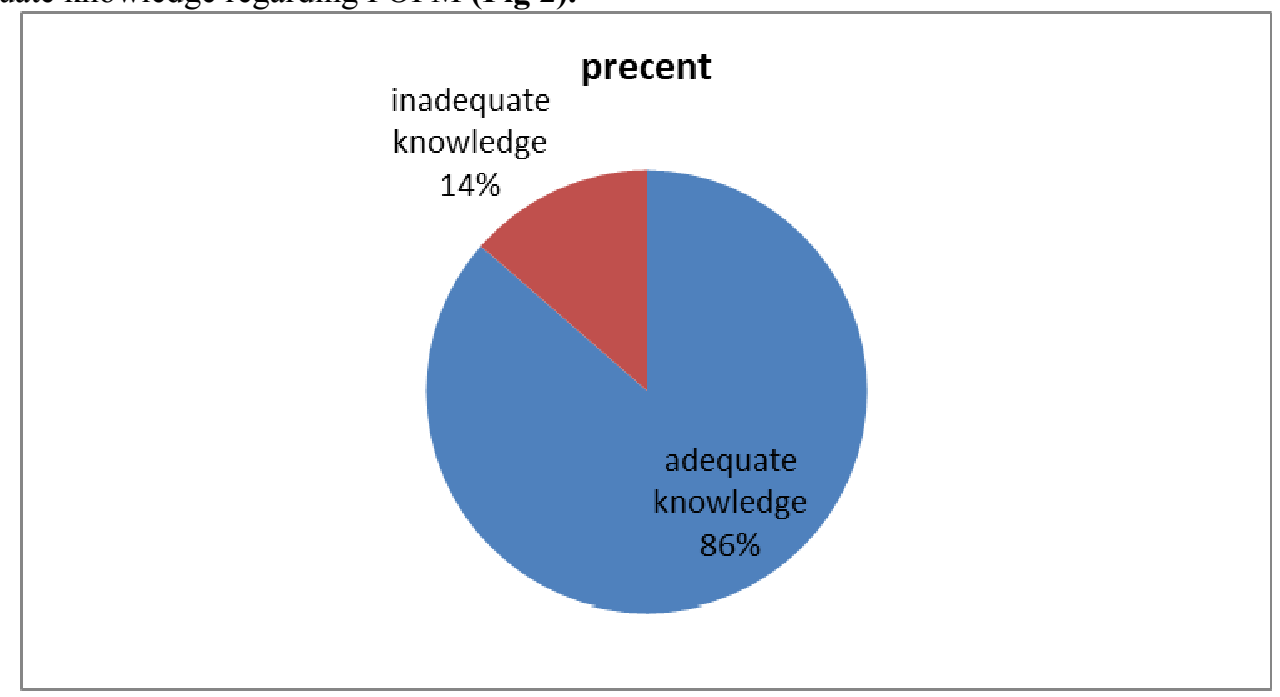

Figure 2: knowledge towards POPM among nurses working in surgical department of selected governmental hospitals in Addis Ababa, Ethiopia, 2019(n=169)

Among the study participants majority $122(72.2 \%)$ of them believe that patient increases amount of analgesics need is because of their psychological dependency, and the remaining about one fourth of the study participants $47(27.8 \%$ ) doesn't believe in this. On a question "Paracetamol tablets is used in managing surgical pain" $122(72.2 \%)$ responded Yes and the rest 47(27.8\%) responded "No". 
Assessment of knowledge on "pharmacological methods: Opioids analgesic such as pethidine and Pentazocine are used to relieve pain in surgical patients" $123(72.8 \%)$ of the participants responded the mentioned medications can be used for surgical patients. Assessment of knowledge on "combining analgesics that work by different mechanisms may result in better pain control with fewer side effects than using a single analgesic." 107(63.3\%) responded "Yes." On a question "pain should be assessed before and after administering pain drugs," majority of the respondents, 152(89.9\%) believed in it (Table 3)

Table 3. Assessment of Knowledge of Respondents

\begin{tabular}{|c|c|c|c|c|}
\hline \multirow[t]{2}{*}{ variables or items } & \multicolumn{2}{|l|}{ Yes } & \multicolumn{2}{|c|}{ No } \\
\hline & $\mathrm{F}$ & $\%$ & $\mathrm{~F}$ & $\%$ \\
\hline $\begin{array}{l}\text { when a patient requests increasing amounts of analgesics to control } \\
\text { pain, this usually indicate that the patient is psychologically } \\
\text { dependent }\end{array}$ & 122 & 72.2 & 47 & $\begin{array}{l}27 . \\
8\end{array}$ \\
\hline Paracetamol tablets is used in managing surgical pain. & 57 & 33.7 & 112 & $\begin{array}{l}66 . \\
3\end{array}$ \\
\hline $\begin{array}{l}\text { cold and heat such as warm bath, sitz bath, ice bags compress should } \\
\text { be used in the management of surgical pain }\end{array}$ & 95 & 56.2 & 74 & $\begin{array}{l}43 . \\
8\end{array}$ \\
\hline $\begin{array}{l}\text { pharmacological methods: opioids analgesic such as pethidine and } \\
\text { pentazocine are used to relieve pain in surgical patients }\end{array}$ & 123 & 72.8 & 46 & 27.2 \\
\hline $\begin{array}{l}\text { combining analgesics that work by different mechanisms may result } \\
\text { in better pain control with fewer side effects than using a single } \\
\text { analgesic agent }\end{array}$ & 107 & 63.3 & 62 & 36.7 \\
\hline pain should be assessed before and after administering pain drugs. & 152 & 89.9 & 17 & 10.1 \\
\hline observation is part of the method used in surgical pain assessment & 136 & 80.5 & 33 & 19.5 \\
\hline $\begin{array}{l}\text { the side effects of narcotics should be observed at least } 20 \text { minutes } \\
\text { after administration }\end{array}$ & 117 & 69.2 & 52 & 30.8 \\
\hline $\begin{array}{l}\text { if the source of pain is not known a pain drug should not be used } \\
\text { during the pain evaluation period because this could mask the ability } \\
\text { to correctly diagnose the cause of pain. }\end{array}$ & 112 & 66.3 & 57 & 33.7 \\
\hline $\begin{array}{l}\text { patients should be encouraged to endure as much pain as possible } \\
\text { before using an opoid }\end{array}$ & 122 & 72.2 & 47 & 27.8 \\
\hline $\begin{array}{l}\text { opoids should not be used in patients with a history of substance } \\
\text { abuse }\end{array}$ & 100 & 59.2 & 69 & 40.8 \\
\hline $\begin{array}{l}\text { rating scale ranging from " } 0 \text { " no pain at all " } 10 \text { " the worst pain is } \\
\text { essential to adopt in pain assessment }\end{array}$ & 114 & 67.5 & 55 & 32.5 \\
\hline $\begin{array}{l}\text { if a patient sleeps with no movement postoperatively, this indicated } \\
\text { that patient is not in pain }\end{array}$ & 62 & 36.7 & 107 & 63.3 \\
\hline
\end{tabular}

\section{Attitude of Nurses towards POPM at Surgical Department}

The highest percentage of nurses strongly disagrees with attitude test questions include; Using pain assessment tool usually make nursing more complicated and consume time for other ward activities $(\mathrm{n}=16,9.5 \%)$. The use of placebo is important in determining if the patient is in real pain are $(n=17,10.1 \%)$. Conversely, the highest percentage of nurses strongly agree with attitude test questions include; Nurses are best judges of the patient's pain intensity because they spent 24 hours with the patients $(n=98,58 \%)$. Pain is seen in the patient's behavior $(n=45,26.6 \%)$. There are too many older patients in acute care hospitals $(n=198,43.3 \%)$, Non-pharmacological interventions are very effective for mild to moderate pain not sever pain and Surgical patients usually do experience pain more intense than medical patients ( $n=66,37.9 \%)$. (Table 4). 
Table 4: Frequency distribution of attitude towards POPM among nurses working in surgical department based on five Likert scales at SPHMMC, Addis Ababa, Ethiopia, 2019(n=169)

\begin{tabular}{|c|c|c|c|c|c|c|}
\hline & Items & $\mathbf{S A}$ & $\mathbf{A}$ & $\mathbf{U N}$ & NA & SD \\
\hline 001 & Pain is seen in the patient's behavior & $77(45.6)$ & $50(29.6)$ & $15(8.9)$ & $19(11.2)$ & $8(4.7)$ \\
\hline 002 & Distraction reduces pain intensity & $45(26.6)$ & $62(36.7)$ & $28(16.6)$ & $22(13)$ & $12(7.1)$ \\
\hline 003 & $\begin{array}{l}\text { Non-pharmacological interventions are very } \\
\text { effective for mild to moderate pain not sever pain }\end{array}$ & $66(39.1)$ & $55(32.5)$ & $17(10.3)$ & $20(11.8)$ & $11(6.5)$ \\
\hline 004 & $\begin{array}{l}\text { The use of placebo is important in determining if } \\
\text { the patient is in real pain }\end{array}$ & $45(26.6)$ & $64(37.9)$ & $31(18.3)$ & $12(7.1)$ & $17(10.1)$ \\
\hline 005 & $\begin{array}{l}\text { Surgical patients usually do experience pain more } \\
\text { intense than medical patients }\end{array}$ & $66(39.1)$ & $63(37.3)$ & $18(10.7)$ & $12(7.1)$ & $10(5.9)$ \\
\hline 006 & $\begin{array}{l}\text { Using pain assessment tool usually make nursing } \\
\text { more complicated and consume time for other } \\
\text { ward activities }\end{array}$ & $42(24.9)$ & $55(32.5)$ & $37(21.9)$ & $19(11.2)$ & $16(9.5)$ \\
\hline 007 & $\begin{array}{l}\text { The nurses personal experience with pain affects } \\
\text { the way the nurses manage pain on surgical } \\
\text { patients }\end{array}$ & $57(33.7)$ & $70(41.4)$ & $18(10.7)$ & $13(7.7)$ & $11(6.5)$ \\
\hline 008 & $\begin{array}{l}\text { Observable changes in vital sign must be relied on } \\
\text { to verify patient's complain of severe pain }\end{array}$ & $56(33.1)$ & $55(32.5)$ & $30(17.8)$ & $16(9.5)$ & $12(7.1)$ \\
\hline 009 & $\begin{array}{l}\text { Nurses are best judges of the patient's pain } \\
\text { intensity because they spent } 24 \text { hours with the } \\
\text { patients }\end{array}$ & $98(58)$ & $50(19.6)$ & $13(7.7)$ & $6(3.6)$ & $2(1.2)$ \\
\hline
\end{tabular}

\section{Practice among Nurses of SPHMMC towards POPM}

The nurses were considered as having good practice if they scored $\geq 70 \%$ out of 10 in the practice assessment questionnaire. The nurses were considered as having poor practice if they scored less than $70 \%$. The result reveals that $99(59 \%)$ of surgical nurses have in adequate knowledge and $70(41 \%)$ have adequate practice regarding POPM (Fig 3)

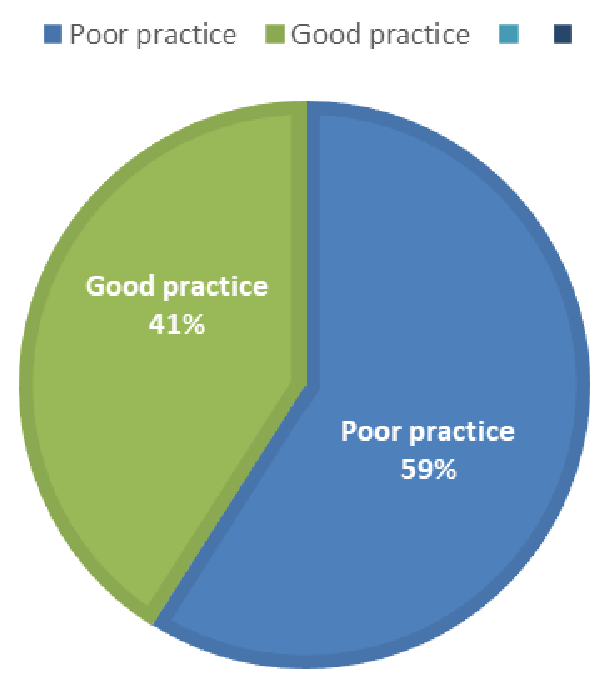

Figure 3: Practice towards POPM among nurses working in surgical department of selected governmental hospitals in Addis Ababa, Ethiopia, 2019(n=169)

\section{Factors Associated with KAP towards POPM among Nurses}

\section{Factors Associated with Nurses Level of Knowledge on POPM}

In the Bivariate logistic regression analysis, the factors found to be candidate for the next model are work experience and educational status. From the variables associated with knowledge of nurses in the bivariate logistic regression; work experience was statistically significant to predict knowledge of nurses in the multivariable logistic regression. Participants who are less than two years of work experience were less likely to have adequate knowledge by $96.2 \%$ than those of having greater than five years work experience. $(\mathrm{AOR}=0.038$, 95\% CI: $(0.007,0.217)$.

Participants with work experience of 3-4 years were less likely to have adequate knowledge by 79.9/100 
than those of having greater than five years work experience. $(\mathrm{AOR}=0.201,95 \% \mathrm{CI}:(0.045,0.906)$.

Table 5:Bivariate and Multivariate analysis of factors associated with practice on POPM among participants in SPHMMC, Addis Ababa Ethiopia, $2019(\mathrm{n}=169) \mathrm{COR}=* \mathrm{P}<0.25 ; \quad$ AOR $* * \mathrm{P}<0.05$

\begin{tabular}{|c|c|c|c|c|c|c|c|}
\hline \multicolumn{2}{|l|}{ Variables } & \multirow{2}{*}{$\begin{array}{l}\begin{array}{l}\text { Good } \\
\text { knowledge }\end{array} \\
3 \\
\end{array}$} & \multirow{2}{*}{$\begin{array}{l}\begin{array}{l}\text { Poor } \\
\text { knowledge }\end{array} \\
102\end{array}$} & \multirow{2}{*}{$\begin{array}{c}\text { P-value } \\
\mathbf{0 . 0 0 1} \\
\end{array}$} & \multirow{2}{*}{$\begin{array}{l}\operatorname{COR}(95 \% \mathrm{CI}) \\
0.037(0.007,0.204) \\
\end{array}$} & \multirow{2}{*}{$\begin{array}{l}\text { P-value } \\
\mathbf{0 . 0 0 0} \\
\end{array}$} & \multirow{2}{*}{$\begin{array}{l}\text { AOR }(95 \% \text { CI }) \\
\mathbf{0 . 0 3 8}(\mathbf{0 . 0 0 7 , 0 . 2 1 7 ) * *}\end{array}$} \\
\hline Work & $<2$ year & & & & & & \\
\hline experience & $3-4$ years & 5 & 36 & 0.040 & $0.222(0.053,0.936)$ & 0.037 & $0.201(0.045,0.906)^{* * *}$ \\
\hline & $\begin{array}{l}>\text { or }=5 \\
\text { years }\end{array}$ & 8 & 13 & 0.232 & 0.545 & 0.232 & 4.215 \\
\hline \multirow{3}{*}{$\begin{array}{l}\text { Level of } \\
\text { education }\end{array}$} & Diploma & 1 & 5 & 0.999 & $0.000(0.000)$ & 0.999 & 0.000 \\
\hline & BSC & 12 & 140 & 0.022 & $0.109(0.016,0.727)$ & 0.055 & $0.114(0.012,1.051)$ \\
\hline & $\begin{array}{l}\text { MSC and } \\
\text { above }\end{array}$ & 3 & 6 & 0.657 & 0.667 & 0.160 & \\
\hline
\end{tabular}

\section{Factors Associated with Nurses' Level of Practice on POPM}

In the Bivariate logistic regression analysis, the factors found to be candidate for the next model were: work experience, and previously trained in post-operative pain management. From the variables associated with practice of nurses in the bivariate logistic regression; work experience, direct providing nursing care on POPM and pain assessment before drug administration was statistically significant to predict practice of nurses in the multivariable logistic regression.

Participants who had work experience of greater than 05 year are eight times having good practice than those nurses having less than two year work experience. $\mathrm{AOR}=8.226(2.143,31.570)$. Participants those having experience pain assessment before and after drug administration had 2.123 times having good practice than have no experience pain assessment before and after drug administration $(\mathrm{AOR}=2.123 \mathrm{CI} ;(1.020,4.418)$. Participants those who did not provide direct nursing care on POPM had $73 \%$ times less likely to have good practice than those who did not proved direct nursing care in POPM. AOR $=0.269 \mathrm{CI} ;(0.107,0.675)$

Table 6: Bivariate and Multivariate analysis of factors associated with practice on POPM among participants in SPHMMC, Addis Ababa city, Ethiopia, June 2019 ( $\mathrm{n}=169)$

\begin{tabular}{|c|c|c|c|c|c|c|c|c|c|}
\hline \multirow{2}{*}{\multicolumn{2}{|c|}{ Variables }} & \multirow{2}{*}{$\begin{array}{l}\text { Good } \\
\text { Practice }\end{array}$} & \multirow{2}{*}{$\begin{array}{l}\text { Poor } \\
\text { practice }\end{array}$} & \multirow{2}{*}{$\begin{array}{l}\mathrm{P}- \\
\text { value }\end{array}$} & \multirow[t]{2}{*}{ COR } & \multirow{2}{*}{\multicolumn{2}{|c|}{$95 \% \mathrm{CI}$}} & \multirow{2}{*}{$\begin{array}{l}\mathrm{P}- \\
\text { value }\end{array}$} & \multirow[t]{2}{*}{ AOR $(95 \% \mathrm{CI})$} \\
\hline & & & & & & & & & \\
\hline \multirow{3}{*}{$\begin{array}{l}\text { Work } \\
\text { experience }\end{array}$} & $<2$ year & 37 & 68 & 0.003 & 0.545 & & & 0.619 & 1.267 \\
\hline & $3-4$ years & 25 & 16 & 0.782 & 1.116 & 0.512 & 2.431 & 0.952 & $1.025(0.450,2.336)$ \\
\hline & $>$ or $=5$ years & 5 & 16 & 0.001 & 8.556 & 2.305 & 31.753 & 0.002 & $8.226(2.143,31.570) * *$ \\
\hline \multirow[b]{2}{*}{$\begin{array}{l}\text { pain } \\
\text { assessment } \\
\text { before and } \\
\text { after drug } \\
\text { administration }\end{array}$} & No & 29 & 27 & 0.057 & 1.939 & & & & \\
\hline & Yes & 40 & 73 & 0.004 & 0.559 & 0.980 & 3.835 & 0.044 & $2.123(1.020,4.418) * *$ \\
\hline \multirow{2}{*}{$\begin{array}{l}\text { direct } \\
\text { providing } \\
\text { Nursing care } \\
\text { POPM }\end{array}$} & No & 19 & 12 & 0.065 & 2.111 & & & & \\
\hline & Yes & 48 & 86 & 0.002 & 0.257 & 0.107 & 0.614 & 0.005 & $0.269(0.107,0.675) * *$ \\
\hline
\end{tabular}

\section{Discussion}

This study aimed at assessing Knowledge, Attitude, Practice and Associated Factors among Nurses Working at SPHMMC Addis Ababa, Ethiopia. The finding of this study revealed that 23(14\%) of nurses' have poor knowledge towards POPM for surgical patient. This is lower than the study conducted in Iran, Isfahan, Al-Zahra hospital which showed $67.2 \%$ of nurses had poor knowledge toward POPM towards surgical patient (23). It is inline the study conducted in acute-care teaching hospital in northern California, which showed that $20 \%$ of the nurses had poor knowledge (25) and higher than the study done in Slovak Republic, Derer Faculty Hospital in which only $9 \%$ of nurses had poor knowledge (24).

The finding of this study is less than the study conducted in Saud Arabia where overall nurses in the three major universities in Saud Arabia had poor knowledge towards POPM (2). Similarly, the study conducted in Bangladesh investigate that in all groups a substantial proportion of participants demonstrated insufficient knowledge about POPM (7).

In this study revealed regarding Knowledge assessment of pain for surgical patient more than half had taken training on pain assessment but a similar study done in Uganda which is lower than to assess nurses' knowledge and practices related to pain assessment indicates $30.6 \%$ had never had any training on pain assessment and management and Out of those who had received some training, majority $83.9 \%$ were not satisfied with the training (8).

This study also found that nurses have negative attitude towards pain management because majority of them (64.5\%) using placebo is important in determining if the patient is in real pain. This shows that the patients are under treated and suffer for their pain because of those misconceptions of the nurses that real pain would not 
relieve by placebo.

With similar study that has been done in Addis Ababa, found that nurses have unfavorable attitude towards pain management because majority of them (72.5\%) thought that using placebo is important in determining if the patient is in real pain. (2)

The study done in Addis Ababa showed that the nurse's level of practice of postoperative pain assessment and management. From all study subjects, 283(87.3\%) of the respondent's practice was low, 21(6.5\%) was moderate and only $20(6.2 \%)$ of respondents practice was high. But in this study shows which relatively lower than $70(41 \%)$ and have poor practice about $99(59 \%)$ of the respondents. (9)

\title{
Conclusion
}

The present study was aiming at assessing the knowledge, attitudes, practices and factors associated in POPM among Nurses at SPHMMC. The overall results show that nurses have good knowledge related to drugs used in pain management. The results also show that the nurses have negative attitudes regarding patients experiencing pain and the use of placebo. The study found that the practices of nurses related to POPM pain are at low level. These, unfavorable attitudinal beliefs and poor practices found in many key areas of pain management have impact on the provision of effective pain management and optimal care given to surgical patients. Several challenges have been identified in this current research by participants/nurses contributing to ineffective pain management. Among those challenges, there is inadequate knowledge about pain assessment and management, ability to assess the pain, fear of other side effects and addiction, pain management is given low priority among health care professionals, lack of pain management in the curriculum during their studies, shortage of staff that leads to work overload and lack of equipment's for patients" monitoring which leads to fear of administering opioids as pain medications.

The attitude of nurses regarding post-operative pain management is negative. Pain assessment tool usually make nursing more complicated and consume time for other ward activities, Conversely, the highest percentage of nurses strongly agree with attitude test questions include; "Nurses are best judges of the patient's pain intensity because they spent 24 hours with the patients" As the nurses are the most important parts in the multidisciplinary approach in pain management, their knowledge and attitude make a big difference on practice POPM. So, there is a need for regular in-service education on pop management according to the recommendation of standard.

\section{Ethical Consideration}

Ethical approval and permission was conducted and granted by the SPHMMC surgical nursing specialty department to conduct the study. All study participants was adequately informed about the purpose, method and anticipated benefit of the study by the data collectors. Written consent was obtained from each participant and confidentiality and anonymity of the study subjects was maintained.

\section{Abbreviations:}

\author{
ASA: American Society of Anesthesiologist \\ CNS: Central Nervous System \\ ENT: Ear, Nose, Throat \\ KAP: Knowledge Attitude Practice \\ MOH: Ministry of Health \\ NRS: Numeric Rating Scale \\ OR: Operating Room \\ POPM: Post-Operative Pain Management \\ PPI: Present Pain Intensity \\ ROS: Reactive Oxygen Species \\ SPHMMC: St. Paul Hospital Millennium Medical College \\ VAS: Visual Analogue Scale
}

\section{Acknowledgments}

We also would like to thank our department, surgical nursing specialty and SPHMM for giving us this opportunity and for facilitating through the whole research process. Our deepest gratitude also goes to individuals who participated as a study sample in this research paper.

\section{Disclosure}

The author reports no conflicts of interest in this work. 


\section{References:}

1. file:///C:/Users/DELL/Downloads/Postoperativepainmanagement-2018consensusstatement...AnaesthesiolIntensiveTher2018.pdf

2. Hailemariam, E., Assessment of postoperative pain management in Saint Paul's Hospital Millennium Medical College. 2015, Addis Ababa University Addis Ababa, Ethiopia.

3. Yüceer, S., Nursing approaches in the postoperative pain management. J Clin Exp Invest www. clinexpinvest. Org

4. Hailemariam, E., Assessment of postoperative pain management in Saint Paul's Hospital Millennium Medical College. 2015, Addis Ababa University Addis Ababa, Ethiopia.

5. https://www.researchgate.net/publication/328848317_Knowledge_Attitudes_and_Practices_of_Postoperative Pain_Management_by_Nurses_in_Selected_District_Hospitals_in_Ghana

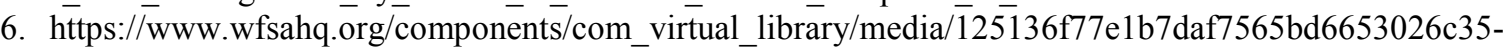
Postoperative-Pain-Management-170518.pdf

7. Woldehaimanot, T.E., T.C. Eshetie, and M.W. Kerie, Postoperative pain management among surgically treated patients in an Ethiopian hospital. PloS one, 2014. 9(7): p. e102835.

8. Basak, S., W. Petpichetchian, and L. Kitrungrote, Knowledge and attitudes of nurses and their practices regarding post-operative pain management in Bangladesh. 2014

9. Vickers, N., Knowledge and attitudes regarding pain among surgical nurses in three teaching hospitals in Ireland. 